\section{Transitory increase in creatinine levels after parathyroidectomy: evidence of another action of the parathyroid glands?}

\author{
Alteração transitória da creatinina após paratireoidectomia: \\ evidência de outra ação das glândulas paratireoides?
}

Fábio M. Montenegro', Lenine G. Brandão', Gustavo F. Ferreira²,

Delmar M. Lourenço Jr. ${ }^{3}$, Regina M. Martin ${ }^{3}$, Malebranche B. Cunha-Neto ${ }^{3}$,

Claudia B. Helou ${ }^{4}$, Sergio A. Toledo ${ }^{3}$, Anói C. Cordeiro', Luiz E. lanhez ${ }^{2}$
1 Head and Neck Surgery, Department of Surgery, Faculdade de Medicina, Universidade de Sao Paulo (FMUSP), SP, Brazil ${ }^{2}$ Renal Transplant Unit, Division of Urology, FMUSP, SP, Brazil ${ }^{3}$ Endocrinology, Department of Internal Medicine, FMUSP, SP, Brazil ${ }^{4}$ Laboratory of Basic Science in Nephrology, Department of Internal Medicine, FMUSP, SP, Brazil , was a slight increase in eGFR (from $94.3 \mathrm{~mL} / \mathrm{min}$ to $105.4 \mathrm{~mL} / \mathrm{min}$, $\mathrm{p}=0.002$ ). Conclusions: Parathyroidectomy may be followed by a transient decrease in eGFR that is not often observed in other head and neck operations. Arq Bras Endocrinol Metab. 2011;55(4):249-55

\title{
Keywords
}

Creatinine; hyperparathyroidism; acute kidney failure; parathyroid hormone; parathyroidectomy

\section{RESUMO}

Objetivo: Há pouca informação sobre alterações da função glomerular após o tratamento cirúrgico do hiperparatireoidismo primário. $O$ efeito agudo sobre a função renal foi estudado após algumas operações em cirurgia de cabeça e pescoço. Materiais e métodos: Análise retrospectiva dos níveis de creatinina e da taxa de filtração glomerular estimada (eGFR). Os valores pré-operatórios foram comparados aos valores disponíveis até 72 horas após a operação. Resultados: No hiperparatireoidismo terciário, os valores médios pré e pós-operatórios da eGFR foram $57,7 \mathrm{~mL} / \mathrm{min}$ e $40,8 \mathrm{~mL} / \mathrm{min}$ ( $p<0,0001$ ), respectivamente. 0 decréscimo após paratireoidectomia por hiperparatireoidismo primário foi de $85,4 \mathrm{~mL} / \mathrm{min}$ para $64,3 \mathrm{~mL} / \mathrm{min}$ (p $<0,0001$ ). Após operações maiores de cabeça e pescoço, houve leve elevação da eGFR (de 94,3 $\mathrm{mL} / \mathrm{min}$ para $105,4 \mathrm{~mL} / \mathrm{min}, \mathrm{p}=0,002$ ). Conclusões: A paratireoidectomia pode ser seguida de uma redução transitória na eGFR que não é frequentemente observada após outras operações em cabeça e pescoço. Arq Bras Endocrinol Metab. 2011;55(4):249-55

Descritores

Creatinina; hiperparatireoidismo; falência renal aguda; hormônio paratireoideo; paratireoidectomia

\section{INTRODUCTION}

$\mathrm{I}^{\mathrm{n}}$ n hyperparathyroidism (HPT), hypocalcemia is the most frequently voiced concern after different modalities of parathyroidectomy. In primary HPT, the postoperative course after resection of parathyroid adenoma is now usually uneventful in developed countries, and many patients are discharged on the day of the operation or on the next day (1). 
However, in renal transplant patients with persistent HPT, acute and transient kidney injury has been described after parathyroidectomy (2). Chronic renal allograft damage was reported after subtotal (3) or total parathyroidectomy with autotransplantation (4).

In one study, there was a consistent correlation between transient decrease in transplanted kidney function and decrease in parathyroid hormone (PTH), shortly after parathyroidectomy (5).

Because of this, we reviewed our own cases of HPT. If creatinine increase is associated with PTH reduction, renal transplant patients who underwent operations not related to the parathyroid glands would exhibit a different pattern. Indeed, while there was a mean increase of $39.5 \%$ in creatinine levels after parathyroidectomy, there was a mean decrease of $2.7 \%$ after other head and neck operations in renal transplant patients (6).

If the increase in creatinine levels is related to decreases in PTH, a similar increase would be expected in patients with primary HPT undergoing parathyroidectomy. The aim of the present study was to evaluate changes in creatinine levels and in estimated glomerular filtration rates (eGFR) after parathyroidectomy or some other head and neck operations, in order to validate our previous observations in a larger number of patients.

\section{MATERIALS AND METHODS}

This retrospective study was approved by the research ethics committee of our institution. We analyzed acute creatinine changes in patients operated on for tertiary HPT after renal transplantation (tHPT) or primary HPT (pHPT), from 1997 to 2007, at the Department of Head and Neck Surgery in the Faculdade de Medicina at Universidade de Sao Paulo. Acute change was defined as occurring in up to 72 hours of the operation.

Results of patients with tHPT and pHPT were compared with observations in random but non-consecutive patients submitted total thyroidectomy (TT), thyroid lobectomy (L), or other major head and neck procedures (MAJOR HNS), as well as kidney transplant patients operated on for non-parathyroid head and neck tumours (NON PTX RENAL TX). MAJOR HNS included malignant and benign diseases (most cases were squamous cell carcinoma of the upper aerodigestive tract, but some cases included parotid tumours, melanoma, skull base surgery, or angiofibroma). For preoperative evaluation, patients usually undergo serum creatinine test from days up to six months prior to the operation. On first day after surgery, MAJOR HNS pa- tients stay at the intensive care unit, and serum creatinine is always included in routine laboratory work up.

At our institution, creatinine is not always requested after thyroidectomy, but the test is carried out in some patients, in conjunction with calcium and/or PTH evaluation, as requested by endocrinologists in other studies. Thus, these results were available for our retrospective analysis.

After our initial observation of a possible acute change in renal function, analysis of postoperative creatinine levels after parathyroidectomy or thyroidectomy became more frequent, but it is still not routine practice. Serum creatinine after thyroidectomy or parathyroidectomy is requested on the preference of the attending surgeon or endocrinologist.

The eGFR was calculated according to the Modification of Diet in Renal Disease (MDRD), using creatinine, age, gender and race, in an internet-based open resource at the National Kidney Foundation, available at http:// www.kidney.org/professionals/kdoqi/gfr_calculator.cfm.

Percent creatinine variation (PCV) was calculated as follows: $\mathrm{PCV}=($ Postoperative Creatinine - Preoperative Creatinine $)$ x 100/(Preoperative Creatinine). A positive value reflects increased creatinine levels and possible decrease in renal function. Percent change of creatinine is a widely accepted tool to evaluate changes in renal function in clinical studies (7). While PCV has its limitations, it prevents the inappropriate comparison of absolute changes in creatinine values between patients with very different basal creatinine levels, i.e., it is not appropriate to compare a $0.5 \mathrm{mg} / \mathrm{dL}$ increase in a patient with basal creatinine level of $0.9 \mathrm{mg} / \mathrm{dL}(55.6 \%$ increase) with that of a patient with preoperative creatinine level of $2.0 \mathrm{mg} / \mathrm{dL}$ ( $25 \%$ increase).

As a retrospective analysis, postoperative creatinine was not available for all patients on every postoperative day. In the present study, the highest value of serum creatinine was employed to calculate PCV only if the measurement was obtained up to the third postoperative day. Tests obtained later were not considered in this study, and these cases were excluded. When available, calcium, phosphorus and PTH levels were included.

Statistical analysis included the Kolmogorov-Smirnov test to assess the normality of distribution. Paired Student's $t$ test was employed for normal distribution and Non-parametric Wilcoxon signed rank test was used for non-normal distribution. One-way ANOVA with Tukey's test or Kruskal-Wallis test for multiple groups with Dunn's Multiple Comparison test for paired group comparison were also employed. Standard deviation is abbreviated as SD. 


\section{RESULTS}

Gender distribution was not comparable in all groups. The proportion of males was higher in patients submitted to major head and neck procedures, as show in table 1. Age distribution differed for MAJOR HNS and TT groups ( $\mathrm{p}<0.05$, Tukey's Multiple Comparison test). In all other situations, mean age was not significantly different.

Mean of available values for total calcium before and after the operation, in patients undergoing total thyroidectomy, were $9.1 \mathrm{mg} / \mathrm{dL}$ and $7.8 \mathrm{mg} / \mathrm{dL}$, respectively. Preoperative and postoperative values were available for 17 cases Preoperative mean was $9.0 \mathrm{mg} / \mathrm{dL}$ and postoperative mean was $7.8 \mathrm{mg} / \mathrm{dL}(\mathrm{p}<0.0001$, paired $t$ test). For lobectomy cases, paired values were available for 7 situations. Their preoperative mean was $8.9 \mathrm{mg} / \mathrm{dL}$ and postoperative mean was $8.2 \mathrm{mg} / \mathrm{dL}$ ( $\mathrm{p}=0.0482$, paired $t$ test $)$.

Mean of available values for total calcium, phosphorus and median of available PTH in patients with tHPT and $\mathrm{pHPT}$ are shown in table 2.

In $\mathrm{pHPT}$, there were 75 cases of parathyroid adenoma. Only one patient required a second operation to achieve success ( $1.33 \%$ of these cases). Creatinine values were available only for the first procedure (when HPT persisted): preoperative level was $0.9 \mathrm{mg} / \mathrm{dL}$ and postoperative level, $0.8 \mathrm{mg} / \mathrm{dL}$.

Of two patients with parathyroid carcinoma, the disease recurred in one of them, who was reoperated three years later. His creatinine values were available on both occasions. In 24 patients with Multiple Endocrine Neoplasia type 1 pHPT (MEN 1), two were reoperated

Table 1. Age and gender distribution

\begin{tabular}{lccc}
\hline & $\mathbf{n}$ & $\begin{array}{c}\text { Mean age } \\
\text { (range) }\end{array}$ & Male:female \\
\hline MAJOR HNS & 54 & $57.3(16-82)$ & $40: 14$ \\
TT & 24 & $43.4(12-72)$ & $8: 16$ \\
L & 9 & $52.7(28-86)$ & $1: 8$ \\
NON PTX RENAL TX & 7 & $50.4(17-76)$ & $3: 4$ \\
t HPT & 41 & $48.8(23-68)$ & $15: 26$ \\
pHPT & 115 & $53(17-83)$ & $32: 83$ \\
\hline
\end{tabular}

approximately fours years after the first operation due to recurrent $\mathrm{pHPT}$. Their creatinine levels were available in both operations. Thus, in the present study, there were 112 patients operated on for pHPT, but there were 115 cases for the comparison of creatinine values (112 patients plus three additional operations). Table 3 shows the distribution of $\mathrm{pHPT}$ cases.

Mean and SD of preoperative creatinine values are depicted in table 4. Distribution of all groups was normal, except for pHPT distribution. Kruskal-Wallis test showed a significant difference in preoperative creatinine values between groups $(\mathrm{p}<0.0001)$. Dunn's multiple comparison test showed that kidney transplant patients had a significantly higher preoperative creatinine levels compared with the other groups; however, mean preoperative creatinine level of tHPT $(1.40 \mathrm{mg} / \mathrm{dL})$ was not statistically different from the mean of the NONPTXTXRENAL group $(1.69 \mathrm{mg} / \mathrm{dL})$ $(\mathrm{p}>0.05)$.

In the MAJOR HNS group, distribution of preand postoperative creatinine levels were normal, and paired Student's $t$ test showed no difference between preoperative and postoperative creatinine levels $(\mathrm{p}=0.11)$. The same was true for the $\mathrm{L}$ group $(\mathrm{p}=0.37)$, NON PTX RENAL TX patients $(\mathrm{p}=0.46)$, and the TT group $(\mathrm{p}=0.16)$.

In patients with $\mathrm{pHPT}$, postoperative creatinine level was significantly higher than preoperative level $(\mathrm{p}<0.0001)$. A similar result was observed in the tHPT group $(\mathrm{p}<0.000 \mathrm{l}$; Wilcoxon signed rank test). When all groups were compared by Kruskal-Wallis test, $\mathrm{p}$ value was $<0.0001$.

Preoperative eGFR of patients undergoing major head and neck surgery was not statistically different from preoperative eGFR of thyroid operations or pHPT, but it was significantly higher than tHPT $(\mathrm{p}<0.001)$ and NONPTX RENAL TX patients $(\mathrm{p}<$ 0.01) (Dunn's Multiple Comparison test). Preoperative eGFR of thyroidectomy patients was higher than that of pHPT $(\mathrm{p}<0.05)$ and renal transplant cases. The eGFR of patients before lobectomy was only different from the eGFR of tHPT cases $(\mathrm{p}<0.05)$. Table 5 shows preoperative and postoperative eGFR values.

Table 2. Values of calcium, phosphorus (in $\mathrm{mg} / \mathrm{dL}$ ) and PTH $(\mathrm{pg} / \mathrm{mL}$ ) before and after the operation

\begin{tabular}{lcccccc}
\hline & $\begin{array}{c}\text { Calcium, } \\
\text { preoperative }\end{array}$ & $\begin{array}{c}\text { Calcium, } \\
\text { postoperative }\end{array}$ & $\begin{array}{c}\text { Phosphorus, } \\
\text { preoperative }\end{array}$ & $\begin{array}{c}\text { Phosphorus, } \\
\text { postoperative }\end{array}$ & $\begin{array}{c}\text { PTH, } \\
\text { preoperative }\end{array}$ & $\begin{array}{c}\text { PTH, } \\
\text { postoperative }\end{array}$ \\
\hline tHPT & 11.4 & 9.2 & 2.7 & 3.8 & 200 & 0 \\
pHPT & 11.7 & 9 & 2.6 & 3.2 & 157.5 & 6 \\
\hline
\end{tabular}


Table 3. Distribution of pHPT cases

\begin{tabular}{lcc}
\hline pHPT & Number of patients & $\begin{array}{c}\text { Number of situations } \\
\text { when creatinine was } \\
\text { analyzed }\end{array}$ \\
\hline Adenoma & 75 & 75 \\
MEN 1 HPT & 24 & 26 \\
Sporadic hyperplasia & 8 & 8 \\
Double adenoma & 2 & 2 \\
Carcinoma & 2 & 3 \\
MEN type 2A HPT & 1 & 1 \\
Total & 112 & 115 \\
\hline
\end{tabular}

Table 4. Pre-and postoperative creatinine levels (mg/dL)

\begin{tabular}{lccc}
\hline & $\begin{array}{c}\text { Mean } \\
\text { preoperative } \\
\text { creatinine (SD) } \\
\text { Range }\end{array}$ & $\begin{array}{c}\text { Mean } \\
\text { postoperative } \\
\text { creatinine (SD) } \\
\text { Range }\end{array}$ & $\mathbf{p}^{*}$ \\
\hline MAJOR HNS & $0.88(0.18)$ & $0.84(0.26)$ & 0.07 \\
TT & $0.54-1.27$ & $0.44-1.55$ & \\
& $0.77(0.22)$ & $0.80(0.27)$ & 0.30 \\
L & $0.45-1.45$ & $0.48-1.54$ & \\
& $0.83(0.37)$ & $0.90(0.37)$ & 0.37 \\
NON PTX RENAL TX & $0.51-1.75$ & $0.57-1.70$ & \\
& $1.69(0.92)$ & $1.57(0.74)$ & 0.46 \\
t HPT & $0.86-3.10$ & $0.80-2.90$ & \\
& $1.40(0.55)$ & $1.92(0.83)$ & $<0.0001$ \\
pHPT & $0.75-3.30$ & $0.80-4.38$ & \\
& $1.04(0.59)$ & $1.38(0.89)$ & $<0.0001$ \\
\hline
\end{tabular}

* Determined by paired $t$ test, except in pHPT (Wilcoxon signed rank test).
Figure 1 is a graphical depiction of eGFR distribution in all groups, excluding cases with preoperative eGFR greater than $150 \mathrm{~mL} / \mathrm{min} / 1.73 \mathrm{sqm}$. Results were not affected by the exclusion of these individuals, and exclusion was done to improve data presentation. Values calculated for PCV of all groups are shown in table 6. Figure 2 shows that the distribution of PCV in the different groups was clearly different in patients undergoing parathyroid surgery.

Table 5. Pre- and postoperative Estimated Glomerular Function Rate (eGFR) in $\mathrm{mL} / \mathrm{min} \times 1.73 \mathrm{sqm}$

\begin{tabular}{lccc}
\hline & $\begin{array}{c}\text { Mean } \\
\text { preoperative } \\
\text { eGFR (SD) }\end{array}$ & $\begin{array}{c}\text { Mean } \\
\text { postoperative } \\
\text { eGFR (SD) }\end{array}$ & $\mathbf{p}^{*}$ \\
\hline MAJOR HNS & $94.3(25.1)$ & $105.4(37.2)$ & 0.0021 \\
TT & $107.4(35.7)$ & $104.7(35.7)$ & 0.54 \\
L & $93.3(29.4)$ & $86.3(30.5)$ & 0.32 \\
NON PTX RENAL TX & $50.7(26.5)$ & $52.7(27.2)$ & 0.62 \\
t HPT & $57.7(20.3)$ & $40.8(15.5)$ & $<0.0001$ \\
pHPT & $85.4(49.1)$ & $64.3(34.0)$ & $<0.0001$ \\
\hline
\end{tabular}

* Determined by paired $t$ test, except in pHPT (Wilcoxon signed rank test).

Table 6. Percent change of creatinine levels

\begin{tabular}{lcccccc}
\hline & t HPT & pHPT & TT & L & $\begin{array}{c}\text { MAJOR } \\
\text { HNS }\end{array}$ & $\begin{array}{c}\text { NON PTX } \\
\text { RENAL TX }\end{array}$ \\
\hline$n$ & 41 & 115 & 24 & 9 & 54 & 7 \\
$\mathrm{PCV}^{*}(\%)$ mean & +39.2 & +33.1 & +4.2 & +11 & -5.3 & -2.7 \\
$\mathrm{PCV}(\%)$ median & +30 & +27 & +1 & -1 & -8.3 & -6.4 \\
\hline${ }^{*} \mathrm{PCV}=$ (Postoperative Creatinine - Preoperative Creatinine) $\times 100 /($ Preoperative Creatinine).
\end{tabular}

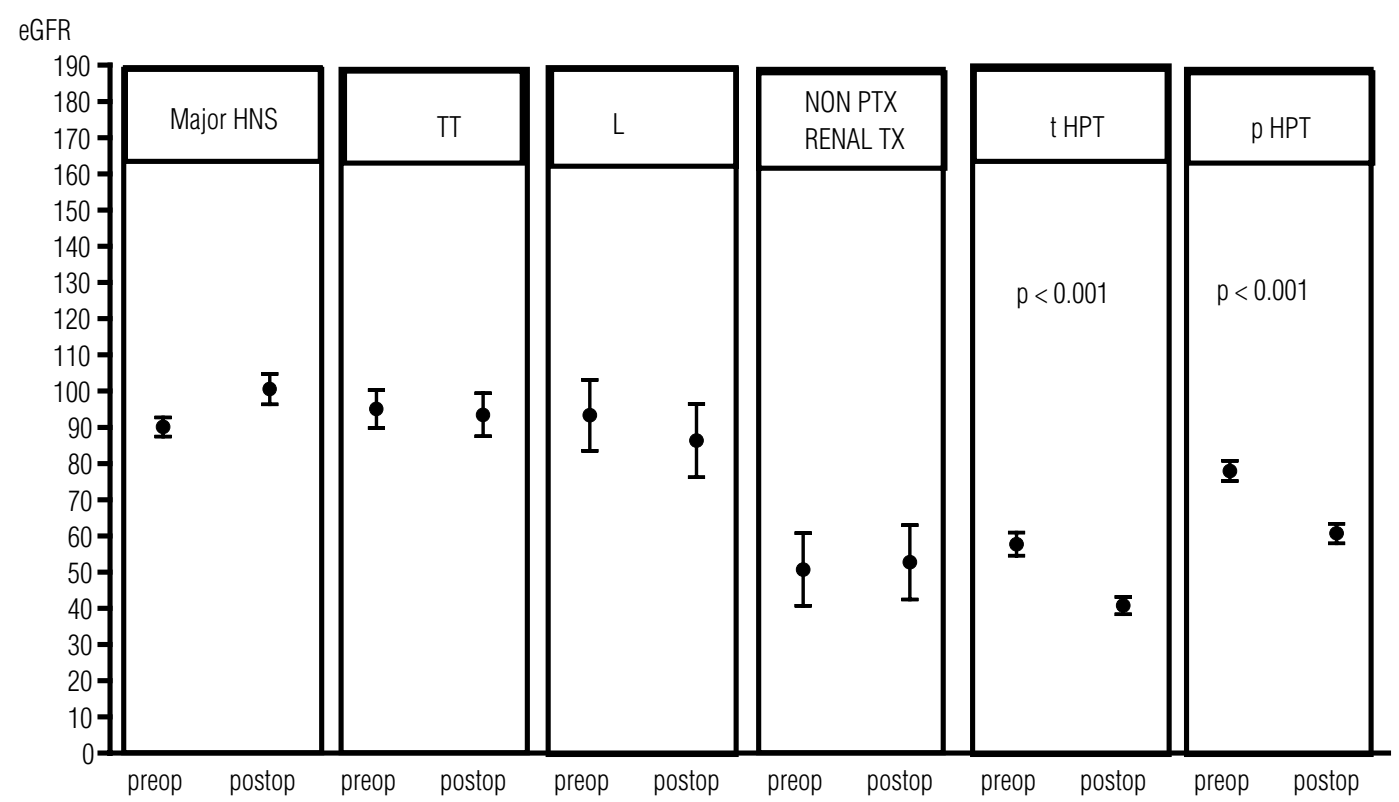

Figure 1. Pre- and postoperative estimated glomerular filtration rate (eGFR). 


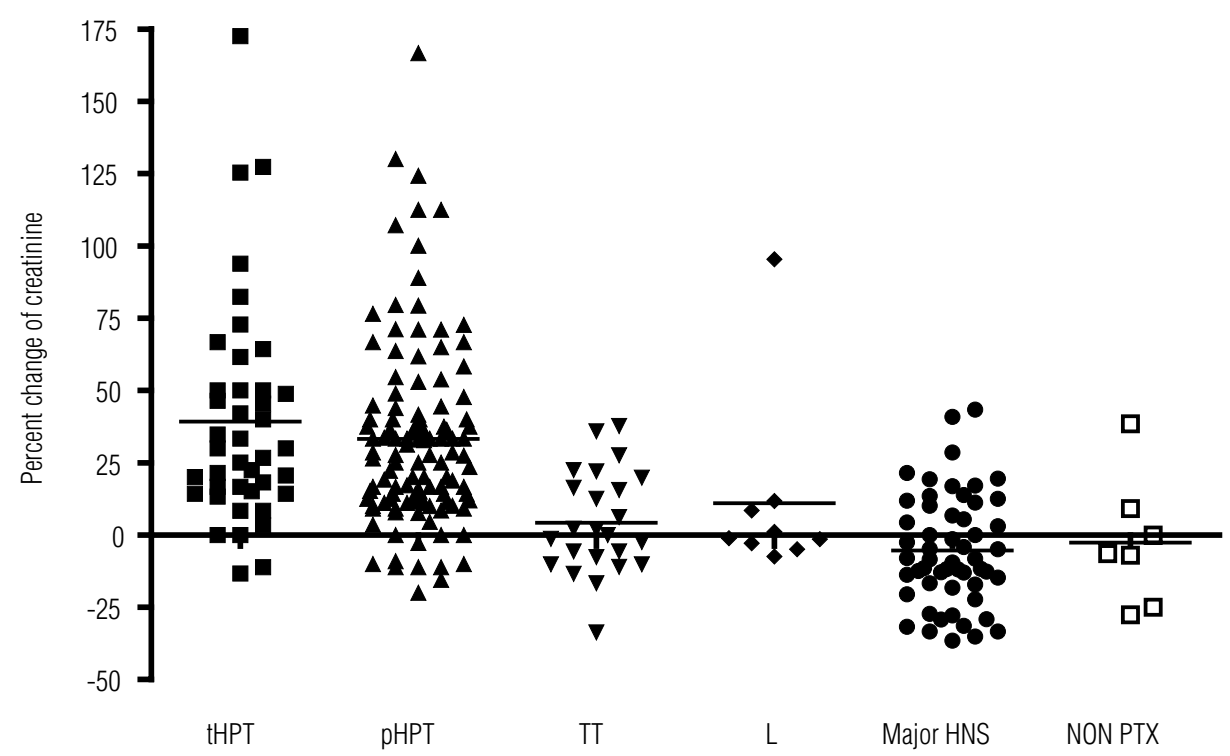

Figure 2. Individual distribution of PCV in all groups (the bar indicates the mean).

\section{DISCUSSION}

Renal changes in HPT are largely and frequently attributable to acute and chronic excessive calcium in the circulation. Thus, resolution of hypercalcemia would theoretically be followed by kidney improvement, if irreversible kidney damage has not occurred.

More recently, however, a transient decrease in renal function after parathyroidectomy for tertiary HPT was correlated with a decrease in PTH levels (5). This led us to review cases of patients with primary HPT. Although resection was performed in only one gland in most cases, a similar acute rise of creatinine was observed. Analysis of this effect on other head and neck procedures showed that creatinine levels were more stable in patients without HPT, except those undergoing thyroidectomy (6). Although this is a retrospective study with many limitations (e.g., time span between sampling, time of day when the blood was obtained, diet or intervening medications), these results are in accordance with the 1958 observations of Edvall on renal function in primary HPT (8).

Acute elevation of creatinine levels after parathyroidectomy in pHPT was briefly discussed by Peacock (9), who apparently demonstrated that this increase was more marked in patients with higher preoperative creatinine levels. However, in another study, we observed that mean eGFR decrease occurred at similar rates, irrespective to preoperative renal function in $\mathrm{pHPT}$ $(-21.8 \%$ in patients with severe to moderate kidney disease, $-30.3 \%$ in mild kidney disease, and $-21.8 \%$ in normal individuals) (10).

In fact, present observations suggest that a more complex pattern can be observed even in patients with lower creatinine levels before the operation. Changes in creatinine levels may be very small, within normal limits and transient, but in other cases, a more marked increase can be detected. It is remarkable that creatinine changes did not exhibit the same pattern in all patients after parathyroidectomy for pHPT. In some of them, it increased while in others it was unchanged, or apparently decreased $(10,11)$.

The retrospective nature of the present study may also interfere with these observations because preoperative creatinine was not measured just before the operation; in some cases, it was measured months prior to surgery. Another problem is the use of only a single postoperative value, which may obscure actual creatinine patterns.

Unfortunately, very important data, such as diabetes and hypertension, could not be retrieved. During the period analyzed, there was no postoperative standard therapy for calcium reposition to avoid hypocalcemia both due to hungry bone syndrome and/or hypoparathyroidism. In relation to hypoparathyroid status, the possibility of hypoparathyroidism after total thyroidectomy could confound the comparison with pHPT. Indeed, the pattern observed in figure 2 shows that the percent increase of creatinine after thyroidectomy seems to be 
halfway between pHPT and Major HNS. For academic purposes, a prospective study would clarify this issue.

Calcium and calcitriol are usually prescribed in hypoparathyroid states. Excessive calcium replacement may have occurred in some cases, although mean postoperative calcium was normal in the present study. Excessive calcium in the circulation seems to cause vasoconstriction of the renal glomerular afferent arteriole. Thus, abrupt drop in PTH, when compared with the slow decrease of excessive calcium in the circulation (caused by natural slow decrease or calcium supplementation), could explain the transient decrease in renal function before normalisation of calcemia. However, results of Lins do not favour this assumption; he observed that renal function does not improve significantly after correction of calcemia following a parathyroidectomy, although a notable improvement in renal function was observed after correction of hypercalcemia in other causes, suggesting a different pattern of PTH-dependent hypercalcemia (12). It should be remembered that changes in intracellular calcium are not currently monitored. Intracellular calcium may play an important, but yet undefined role. The same might be true for calcium-sensing receptors in the kidney.

An important point to be addressed is parathyroid secretion, which is abruptly changed by parathyroidectomy, as observed in the present series (Table 2). Is PTH itself directly affecting renal function? Do direct physiological actions of PTH on renal function clearly explain present observations? In one study, postoperative creatinine changes were only correlated to the degree of PTH decrease after parathyroidectomy in renal transplant patients (5).

In relation to circulatory or renal effects of active PTH fragments or parathyroid extract infusion, Massry and cols. noted that many contradictory results have been published (13). One possible clinical model to observe PTH action on renal function is its clinical use in osteoporosis treatment. In a randomised trial with subcutaneous injection of 1-34 PTH, a significant increase in serum creatinine was observed after the fourth month of treatment (14). It is curious that in a study with 1-84 PTH injection, measured creatinine clearance tended to increase in PTH-treated patients, but remained relatively stable in placebo patients (15). Considering these facts and the present observations, one may wonder if direct and indirect effects of different PTH fragments on renal function deserve further basic research.
In the present series, postoperative creatinine changes could be, in part, related only to the use of drugs, such as nonsteroidal anti-inflammatory drugs (NSAIDs), during surgery, a rather common practice in anaesthesia (16). Indeed, Lee and cols. concluded that NSAIDs cause a clinically unimportant transient reduction in renal function in the early postoperative period (16). Another possibility would be that HPT patients are more sensitive to the nephrotoxic effects of a NSAID or other agents commonly employed in anesthesia. Could a recent parathyroidectomy aggravate the nephrotoxicity of some drugs and affect present results? In experimental studies, parathyroidectomy was demonstrated to be associated with reduced nephrotoxicity of cisplatin (17) and gentamicin (18). The mechanism for this kind of protection was unclear.

Transitory creatinine increase may be clinically unimportant, but its impact on long-term renal function is presently unknown. Until proven otherwise, however, the present observation may point out that any potential nephrotoxic drug should be avoided or used judiciously during or early after parathyroidectomy. Perhaps a parallel with contrast induced nephropathy may be of value. Are we able to identify patients at risk or define protective measures when planning the treatment of patients with acute reduction of parathyroid function? (19).

An increase in creatinine levels not reflecting an actual reduction in glomerular renal function may be questioned in the present series. The possible interference on tubular secretion of creatinine should be taken into account (20). Thus, creatinine increase would not represent glomerular renal change, but only reduced tubular secretion of the marker. However, some patients presented oliguria after parathyroidectomy in the middle of the last century, as noted by Fuller Albright (11). Another hint to a real renal dysfunction is the rare but alarming acute effect on chronic kidney injury that occurs in some patients immediately after parathyroidectomy $(21,22)$. This problem may be underreported in the literature, as physicians may consider that other causes of acute kidney injury may lead to acute or chronic renal disease after parathyroidectomy, in primary HPT patients with some degree of chronic kidney disease.

Alternatively, one may suggest that "spontaneous" increase in creatinine occurs in hospitalised patients, based on a recent paper questioning the overestimation of contrast induced nephropathy (23). It is pos- 
sible that creatinine increases spontaneously in different measurements; however, a careful reading of the study shows that the authors are not saying that at all: they only demonstrate that creatinine may change due to other factors affecting renal function, besides radiological contrast. In their retrospective analysis, they could not rule out other potential risk factors to renal damage in the hospitalised population (23). The same criticism may be applied to the present study: as creatinine was not routinely requested, we may have included in the analysis patients presenting more risk factors.

The present data showed there was a significant improvement in eGFR in patients undergoing major head and neck operations. This may be explained by overhydration during the operation and early postoperative period of these long operations. Low creatinine concentrations may be induced by overhydration (24).

In conclusion, a significant and transient change in creatinine levels may be observed right after parathyroidectomy. The mechanism underlying this phenomenon is apparently not yet understood. In our view, further basic research on the effects of different PTH fragments on renal function may be of scientific interest.

Disclosure: no potential conflict of interest relevant to this article was reported.

\section{REFERENCES}

1. Sitges-Serra A, Bergenfelz A. Clinical update: sporadic primary hyperparathyroidism. Lancet. 2007;370:468-70.

2. Evenopoel P, Claes K, Kuypers D, Maes B, Vanrenterghem Y. Impact of parathyroidectomy on renal graft function, blood pressure and serum lipids in kidney transplant recipients: a single centre study. Nephrol Dial Transplant. 2005;20:1714-20.

3. Lee P, Schiffmann L, Offermann G, Beige J. Effects of parathyroidectomy on renal allograft survival. Kidney Blood Press Res. 2004:27:191-6.

4. Schlosser K, Endres N, Celik I, Fendrich V, Rothmund M, Fernández E. Surgical treatment of tertiary hyperparathyroidism: the choice of procedure matters! World J Surg. 2007;31(10):1947-53.

5. Schwarz A, Rustien G, Merkel S, Rademacher J, Haller H. Decreased renal transplant function after parathyroidectomy. Nephrol Dial Transplant. 2007;22(2):584-91.

6. Montenegro FLM, Ferreira GF, Lourenço Jr DM, Martin RM, Arap SS, Correa PH, et al. Transitory decrease of renal function after parathyroidectomy: a clinical observation indicating the renal hemodynamic effect of parathyroid hormone? Rev Bras Cir Cabeça Pescoço. 2007;36(4):196-201.
7. Solomon R, Segal A. Defining acute kidney injury: what is the most appropriate metric? Nat Clin Pract Nephrol. 2008;4(4):208-15.

8. Edvall CA. Renal function in hyperparathyroidism: a clinical study of 30 cases with special reference to selective renal clearance and renal vein catheterization. Acta Chirur Scand Suppl. 1958;114(Suppl 229):1-56.

9. Peacock M. Primary hyperparathyroidism and the kidney: biochemical and clinical spectrum. J Bone Min Res. 2002;17(Suppl 2):N87-94.

10. Montenegro F, Martin RM, Lourenço Jr DM, Arap SS, Nascimento $\mathrm{Jr} \mathrm{CP}$, Brandão LG. Alteração transitória da taxa de filtração glomerular após paratireoidectomia independe da função renal pré-operatória. Rev Bras Cir Cabeça Pescoço. 2010;39(2):99-102.

11. Montenegro F, Martin R, Lourenço Jr D. The parathyroids and the Kidney: Fuller Albright revisited. World J Surg. 2009;33:246-7.

12. Lins LE. Renal function in hypercalcemia. A clinical and experimental study. Acta Med Scand Suppl. 1979;632:1-46.

13. Massry SG, Coburn JW, Friedler RM, Kurokawa K, Singer FR. Relationship between the kidney and parathyroid hormone. Nephron. 1975;15(3-5):197-222.

14. Hodsman AB, Fraher LJ, Watson PH, Ostbye T, Stitt LW, Adachi $\mathrm{JD}$, et al. A randomized controlled trial to compare the efficacy of cyclical parathyroid hormone versus cyclical parathyroid hormone and sequential calcitonin to improve bone mass in postmenopausal women with osteoporosis. J Clin Endocrinol Metab. 1997;82:620-8.

15. Hodsman AB, Hanley DA, Ettinger MP, Bolognese MA, Fox J, Metcalfe $A J$, et al. Efficacy and safety of human parathyroid hormone-(1-84) in increasing bone mineral density in postmenopausal osteoporosis. J Clin Endocrinol Metab. 2003;88:5212-220.

16. Lee A, Cooper MG, Craig JC, Knight JF, Keneally JP. Effects of nonsteroidal anti-inflammatory drugs on postoperative renal function in adults with normal renal function. Cochrane Database Syst Rev. 2007;(2):CD002765.

17. Capasso G, Giordano DR, Tommaso G, Santo NG, Massry SG. Parathyroidectomy has a beneficial effect on experimental cisplatin nephrotoxicity. Clin Nephrol. 1990;33(4):184-91.

18. Bennet WM, Pulliam JP, Porter GA, Houghton DC. Modification of experimental gentamicin nephrotoxicity by selective parathyroidectomy. Am J Physiol. 1985;249(6Pt2):F832-5.

19. Montenegro F, Fernandes GF, lanhez LE. Surgical treatment of tertiary hyperparathyroidism: the choice of procedure matters! [letter] World J Surg. 2008;32(8):1892-3.

20. Rodríguez-Iturbe B, Herrera J, Marín C, Mañalich R. Tubular stress test detects subclinical reduction in renal functioning mass. Kidney Int. 2001;59:1094-102.

21. Laroche $M$, Garrette F, Rostaing $L$, Catagrel A, Mazières B. End-stage renal failure following parathyroidectomy for advanced primary hyperparathyroidism. Rev Med Interne. 1998;19(11):787-91.

22. Montenegro FL, Martin RM, Correa PH. Acute renal failure after parathyroidectomy: is the reduction of parathyroid function a risk factor? Clinics. 2009;64(4):269-72.

23. Newhouse JH, Kho D, Rao QA, Starren J. Frequency of serum creatinine changes in the absence of iodinated contrast material: implications for studies of contrast nephrotoxicity. AJR.2008;191:376-82.

24. Lameire N, Van Biesen W. The initiation of renal replacement therapy-just in time delivery. N Engl J Med. 2010;363(7):678-80. 